\title{
Carotid intima-media thickness and inflammatory biomarkers in adolescents with tension-type headache
}

\author{
Agnieszka Cwalińska' ${ }^{1}$ Anna Mania', Katarzyna Mazur-Melewska'1, Paweł Kemnitz', \\ Katarzyna Jończyk-Potoczna'², Wojciech Służewski', Magdalena Figlerowicz ${ }^{1}$ \\ 'Department of Infectious Diseases and Child Neurology, Poznan University of Medical Sciences, Poznan, Poland \\ ${ }^{2}$ Department of Paediatric Radiology, Poznan University of Medical Sciences, Poznan, Poland
}

\section{ABSTRACT}

Introduction: Primary headaches are frequent complaints among adolescents. Tension-type headache (TTH), which causes symptoms influencing the patients' quality of life, can be associated with various medical disorders.

Aim of the study: To research the reason for TTH in adolescents.

Material and methods: The study included 76 patients, aged from 14 to 17 years, diagnosed due to TTH. Patients with the carotid intima-media thickness (cIMT) in the $90^{\text {th }}$ percentile (the cut-off point: $0.42 \mathrm{~mm}$ for boys, and $0.41 \mathrm{~mm}$ for girls) were included in group 1, and the rest in group 2. All the patients underwent laboratory tests with serum levels of IL-6, IL-10, TNF- $\alpha$, and sICAM-1. Twenty-six (34\%) patients were enrolled in group 1 and $50(66 \%)$ in group 2.

Results: There were no significant differences in age, sex, height, BMI, and systolic and diastolic blood pressure between patients from both studied groups. The mean cIMT value (mean, SD) for all patients from the study group was $0.41 \pm 0.012 \mathrm{~mm}$ : for girls $0.39 \pm 0.014 \mathrm{~mm}$ and for boys $0.44 \pm 0.016 \mathrm{~mm}$. In 16-year-old adolescents, the cIMT was significantly higher in boys than girls. In 17-year-old patients, cIMT was significantly higher in boys only in group 1 . The significantly higher concentrations of IL-6, TNF- $\alpha$, and sICAM-1 were found in patients from group 1 . Whereas the IL-10 level was significantly higher in the control group. In over one-third of patients (34\%) with TTH, the cIMT was in the $90^{\text {th }}$ percentile, despite having normal BMI, blood pressure, and lipid profile in serum.

Conclusions: The inflammatory process in the vascular wall could be considered as the reason for the higher cIMT value and/or TTH in adolescents.

\section{KEY WORDS:}

biomarkers, adolescents, carotid intima-media thickness, tension-type headache.

\section{INTRODUCTION}

Primary headaches, including migraine and tension-type headache (TTH), are frequent complaints among adolescents $[1,2]$. The prevalence of headaches is estimated to be $27-32 \%$ at the age of $13-14$ years, increas- ing with age $[2,3]$. TTH cause symptoms influencing patients' quality of life, school attendance, and daily activity.

TTH can be associated with various medical disorders, chronic psychiatric, and neurological diseases (for example sleep disorder, anxiety, depression, epilepsy, attention deficit, and hyperactivity disorders) as well as

\section{ADDRESS FOR CORRESPONDENCE:}

Magdalena Figlerowicz, Department of Infectious Diseases and Child Neurology, Poznan University of Medical Sciences, 27/33 Szpitalna St., 60-572 Poznan, ORCID: 0000-0003-4731-0658, e-mail: mfiglerowicz@gmail.com 
cardiovascular diseases, such as transient ischaemic attack or stroke [4-6].

Atherosclerosis could be the cause of the latter. Atherosclerosis is known to be associated with a higher level of low-density lipoprotein as well as total cholesterol in the blood, impaired glucose tolerance and diabetes, obesity, hypertension, and tobacco smoking [7]. It has also been proven that chronic inflammation contributes to accelerated atherogenesis and plays an essential role in all stages the process, from fatty streak formation, through atheroma progression, to the development of thrombosis, as well as plaque rupture [8]. When the disease is still in a subclinical stage, the presence of atherosclerosis can be identified by several methods ranging from B-mode ultrasonography, intravascular ultrasonography, and coronary angiography to computed tomography and magnetic resonance imaging. Several studies have shown that the measurement of the common carotid artery intima-media thickness (IMT) represents a perfect marker of subclinical atherosclerosis [9-11]. Other studies have proven that IMT is very weak predictor of cardiovascular events [12] and progression of IMT does not predict cardiovascular events. According to some studies, IMT and atherosclerosis are biologically and genetically determined [13-15].

One of the causes of atherosclerosis could be a progressive inflammatory process in the vascular wall, which provides signals for leukocyte and macrophage infiltration [9]. Additionally, the cytokines released as a part of the inflammatory cascade stimulate the production of interleukin 1 (IL-1) and interleukin 6 (IL-6), which in turn lead to the excessive output of other acute reactants such as tumour necrosis factor $\alpha$ (TNF- $\alpha$ ). Moreover, it is well known that serum concentration of the soluble form of intracellular adhesion molecule (sICAM-1) is associated with many cardiovascular disease risk factors including body mass index (BMI), blood pressure, and lipid disorders [8].
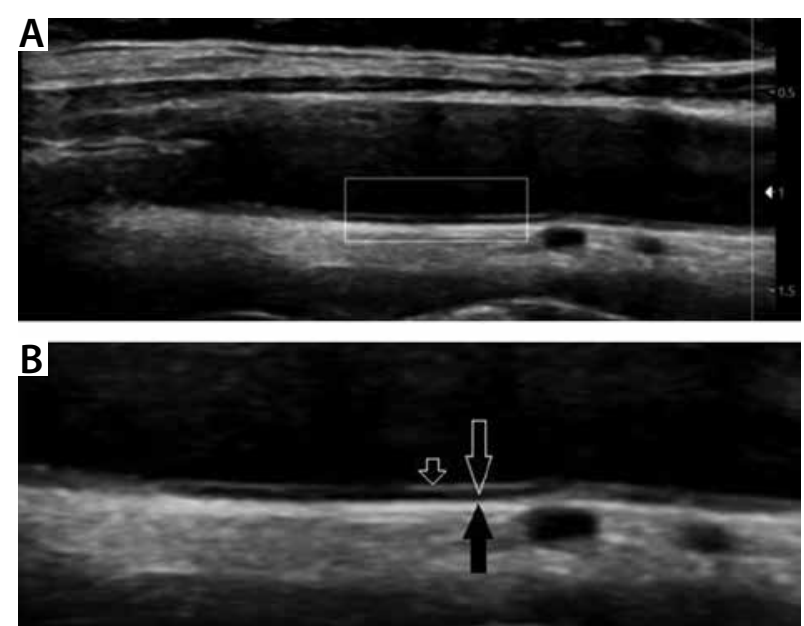

FIGURE 1. A) B-mode ultrasound of the common carotid artery, B) closeup of the far wall, illustrating the intimae (short arrow), medial (long arrow), and adventitial (black arrow) layers

\section{MATERIAL AND METHODS}

The study included 76 patients $(n=76)$, aged 16.48 \pm 1.52 years, 40 girls ( $53 \%$ ) and 36 boys (47\%), diagnosed due to TTH. Prior to inclusion in the study diagnostic procedures were conducted, and as a result persons with psychiatric and neurological diseases, heart defects, acute infection caused by cytomegalovirus and Epstein-Barr virus, and laboratory evidence of lipid disorders were excluded. In all patients, blood pressure (BP) and carotid intima-media thickness (cIMT) were measured. Body mass index (BMI) was calculated basing on the formula: body weight $(\mathrm{kg}) /$ body height $\left(\mathrm{m}^{2}\right)$. Carotid ultrasound was performed with a Philips Healthcare IU 22 scanner, using a $10-\mathrm{MHz}$ linear transducer, according to the cIMT measurement scheme published in 2006 at the Mannheim Intima-Media Thickness Consensus [9]. cIMT measurements were performed on both sides of the common carotid artery $(2 \mathrm{~cm}$ below the bifurcation), the carotid bulb, and in the internal carotid artery. The study was carried out on the patient in supine position with two access method: front with a slight headto-back, and posterolateral next to the sternomastoid muscle. The transducer plane was oriented parallel to the course of the vessel so that the ultrasonic beam was perpendicular to the artery wall. In the $2 \mathrm{D}$ presentation, a distal wall was seen, within which cIMT assumed the distance between the first linear hyperechogenic vascular structure, starting from its light, and the median separating line from the adductor (Fig. 1). The obtained results (10 measurements in each section on each side) are presented as the arithmetic mean for all projections. The group was divided into two subgroups according to the cIMT value. The $90^{\text {th }}$ percentile was adopted as the cut-off point: $0.42 \mathrm{~mm}$ cIMT for boys and $0.41 \mathrm{~mm}$ cIMT for girls. Patients with a cIMT value of $90 \%$ or higher were included in group 1, and the rest in group 2 (control group). All the patients underwent laboratory tests including serum levels of IL-6, IL-10, TNF- $\alpha$, and sICAM-1.

Continuous variables were expressed as mean \pm standard deviation (SD). For comparison of the continuous variables, the Mann-Whitney $U$ test was used, and the chi-square or Fisher's exact test was used for comparison of categorical data. Pearson's correlation coefficient method was used to assess the correlation between cIMT and IL-6, IL-10, TNF- $\alpha$, and sICAM-1. Statistical analyses were performed using Statistica 8.0, StatSoft. The study was approved by the local Bioethical Committee.

\section{RESULTS}

The studied group comprised 40 (53\%) girls and 36 (47\%) boys with TTH. Based on a cIMT value higher than the $90^{\text {th }}$ percentile (cIMT was determined for the studied group, cut-off points for male $0.42 \mathrm{~mm}$ and for female $0.41 \mathrm{~mm}), 26(34 \%)$ patients were enrolled in group 1: 15 boys, and 11 girls. Other patients - 50 (66\%) adolescents: 21 boys and 29 girls, were included in group 2 . 
There were no significant differences in age, sex, height, BMI, and systolic and diastolic blood pressure between patients from both studied groups (Table 1).

The mean cIMT value (mean, SD) for all patients from the study group was $0.41 \pm 0.012 \mathrm{~mm}$ : for girls 0.39 $\pm 0.014 \mathrm{~mm}$ and for boys $0.44 \pm 0.016 \mathrm{~mm}$. There were 14 patients in the age of 14 years $(18 \%), 18$ in the age of 15 years (24\%), 21 in the age of 16 years (28\%), and 23 in the age of 17 years $(30 \%)$. The mean cIMT value and SD for 14-year-old patients was $0.37 \pm 0.015 \mathrm{~mm}$; for 15 -year-old patients it was $0.39 \pm 0.008 \mathrm{~mm}$; for 16 -yearold-patients it was $0.42 \pm 0.012 \mathrm{~mm}$, and for 17 -year-old patients it was $0.43 \pm 0.015 \mathrm{~mm}$.

In 14- and 15-year-old patients, there were no statistically significant differences in cIMT values between girls and boys in group 1 as well as group 2. In 16-year-old adolescents, the cIMT value was significantly higher in boys than in girls, both in group $1(p=0.036)$ and in group 2 $(p=0.022)$. In 17-year-old patients, cIMT values were significantly higher in boys than in girls only in group 1 $(p=0.011)$ (Table 2).

The levels of analysed cytokines and SICAM-1 were established and compared between both groups (Table 3). Significantly higher concentrations of IL-6, TNF- $a$, and sICAM-1 were found in patients in group 1 (respectively, $p<0.001, p<0.001$, and $p<0.001$ ), whereas the IL-10 level was significantly higher in the control group $(p<0.005)$. In whole studied group of patients, the correlation between cIMT values and the concentration of cytokines were established for: IL-6 $r=0.7398$, TNF- $\alpha r=0.7623$, sICAM-1 $r=0.7825$, and for IL-10 $r=-0.5869$ (Fig. 2). No correlation was found between cIMT and: severity of TTH, BMI, weight, or blood pressure.

\section{DISCUSSION}

In the whole group of 76 patients with TTH girls slightly predominated, but without significant statistical
TABLE 1. General characteristics of the study population $(n=76)$

\begin{tabular}{|l|c|c|c|}
\hline Characteristic & $\begin{array}{c}\text { Group 1 } \\
\text { (cIMT } \geq 90^{\text {th }} \\
\text { percentile) }\end{array}$ & $\begin{array}{c}\text { Group 2 } \\
\text { (cIMT < 90 } \\
\text { percentile) }\end{array}$ & $p^{*}$ \\
\hline No. of subjects & 26 & 50 & \\
\hline $\mathrm{M}$ & 15 & 21 & 0.578 \\
\hline $\mathrm{F}$ & 11 & 29 & 0.546 \\
\hline
\end{tabular}

\begin{tabular}{|l|l|l|l|}
\hline \multicolumn{4}{|l|}{ Age, years } \\
\hline $\mathrm{M}$ & $15.83 \pm 1.14$ & $16.34 \pm 1.66$ & 0.534 \\
\hline $\mathrm{F}$ & $15.25 \pm 2.75$ & $16.14 \pm 1.20$ & 0.485 \\
\hline
\end{tabular}

\begin{tabular}{|l|c|c|c|}
\hline \multicolumn{4}{|l|}{ Height, $\mathrm{cm}$} \\
\hline $\mathrm{M}$ & $162.4 \pm 11.5$ & $163.5 \pm 6.5$ & 0.562 \\
\hline $\mathrm{F}$ & $162.8 \pm 7.3$ & $165.5 \pm 6.8$ & 0.463 \\
\hline $\mathrm{BMI}, \mathrm{kg} / \mathrm{m}^{2}$ & \multicolumn{3}{l|}{} \\
\hline $\mathrm{M}$ & $21.5 \pm 2.0$ & $21.4 \pm 2.5$ & 0.676 \\
\hline $\mathrm{F}$ & $20.5 \pm 3.1$ & $21.2 \pm 3.2$ & 0.753 \\
\hline
\end{tabular}

Systolic BP, mm Hg

\begin{tabular}{l|l|l|l|}
\hline $\mathrm{M}$ & $118.1 \pm 7.2$ & $117.1 \pm 7.1$ & 0.689 \\
\hline $\mathrm{F}$ & $113.1 \pm 8.3$ & $106.5 \pm 6.8$ & 0.724 \\
\hline \multicolumn{4}{|l}{ Diastolic BP, mm Hg } \\
\hline $\mathrm{M}$ & $59.5 \pm 4.5$ & $59.8 \pm 7.3$ & 0.426 \\
\hline $\mathrm{F}$ & $61.2 \pm 6.2$ & $65.2 \pm 2.4$ & 0.527 \\
\hline
\end{tabular}

CIMT- carotid intima-media thickness, $F$ - female, $M-$ men, BMI - body mass index, $B P$ - blood pressure, $c I M T \geq 90^{\text {th }}$ percentile - cut-off points $M=0.42 \mathrm{~mm}, F=0.41 \mathrm{~mm}$, " analysis of variance with one parameter, $p<0.05$

differences. The number of adolescents who were diagnosed because of TTH increased with age, from 14 persons at the age of 14 years, to 23 persons at the age of 17 years. According to a study conducted on a larger population, sex differences were not observed before puberty (only a slight male predominance). Conversly, later, after puberty, a meaningful increase in the frequency of TTH in girls is noticed (with ratio $2.5: 1$ ). The tendency for

TABLE 2. Carotid intima-media thickness values in the examined groups depending on the age and sex of patients

\begin{tabular}{|c|c|c|c|c|c|c|c|}
\hline \multirow[b]{2}{*}{$\begin{array}{l}\text { Age }^{*} \\
\text { (years) }\end{array}$} & \multirow[b]{2}{*}{ Sex } & \multicolumn{3}{|c|}{ Group 1 (cIMT $\geq 90^{\text {th }}$ percentile) } & \multicolumn{3}{|c|}{ Group 2 (cIMT $<90^{\text {th }}$ percentile) } \\
\hline & & $n=26$ & $\begin{array}{l}\text { cIMT }(\mathrm{mm}) \\
\text { (mean, SD) }\end{array}$ & $p^{* *}$ & $n=50$ & $\begin{array}{l}\text { cIMT (mm) } \\
(\text { mean, SD) }\end{array}$ & $p^{* *}$ \\
\hline \multirow[t]{2}{*}{14} & M & 2 & $0.48 \pm 0.013$ & \multirow[t]{2}{*}{ NC } & 4 & $0.34 \pm 0.012$ & \multirow[t]{2}{*}{0.524} \\
\hline & $\mathrm{F}$ & 1 & 0.46 & & 7 & $0.34 \pm 0.008$ & \\
\hline \multirow[t]{2}{*}{15} & M & 3 & $0.49 \pm 0.006$ & \multirow[t]{2}{*}{0.528} & 7 & $0.38 \pm 0.021$ & \multirow[t]{2}{*}{0.512} \\
\hline & $\mathrm{F}$ & 2 & $0.46 \pm 0.013$ & & 6 & $0.34 \pm 0.003$ & \\
\hline \multirow[t]{2}{*}{16} & M & 5 & $0.53 \pm 0.014$ & \multirow[t]{2}{*}{0.036} & 5 & $0.40 \pm 0.001$ & \multirow[t]{2}{*}{0.022} \\
\hline & $\mathrm{F}$ & 3 & $0.46 \pm 0.013$ & & 8 & $0.36 \pm 0.001$ & \\
\hline \multirow[t]{2}{*}{17} & M & 5 & $0.53 \pm 0.001$ & \multirow[t]{2}{*}{0.011} & 5 & $0.40 \pm 0.001$ & \multirow[t]{2}{*}{0.501} \\
\hline & $\mathrm{F}$ & 5 & $0.48 \pm 0.013$ & & 8 & $0.38 \pm 0.001$ & \\
\hline
\end{tabular}

"age: 14 ( $\geq 14<15), 15(\geq 15<16), 16(\geq 16<17), 17(\geq 17<18)$, cIMT - carotid intima-media thickness, $M-$ men, $F-$ female, cIMT $\geq 90^{\text {th }}$ percentile - cut-off points $M=0.42 \mathrm{~mm}, F=0.41 \mathrm{~mm}$, analysis of variance with one parameter, $p<0.05, N C$ - has not been calculated 
TABLE 3. Serum cytokines levels in patients with carotid intima-media thickness $\geq 90^{\text {th }}$ percentile and $<90^{\text {th }}$ percentile

\begin{tabular}{|c|c|c|c|}
\hline Cytokines & $\begin{array}{c}\text { Group } 1 \\
\text { (cIMT } \geq 90^{\text {th }} \text { percentile) } \\
n=26\end{array}$ & $\begin{array}{c}\text { Group } 2 \\
\text { (cIMT }<90^{\text {th }} \text { percentile) } \\
n=50\end{array}$ & $p^{*}$ \\
\hline $\begin{array}{l}\mathrm{IL}-6(\mathrm{pg} / \mathrm{ml}) \\
\text { mean, SD } \\
\text { (range, median) }\end{array}$ & $\begin{array}{c}14.1 \pm 7.5 \\
(6.4-18.5,5.1)\end{array}$ & $\begin{array}{c}9.8 \pm 4.3 \\
(0.0-12.2,2.3)\end{array}$ & $<0.001$ \\
\hline $\begin{array}{l}\text { TNF- } \alpha \text { (pg/ml) } \\
\text { mean, SD } \\
\text { (range, median) }\end{array}$ & $\begin{array}{c}29.5 \pm 8.4 \\
(2.8-4.5,14.8)\end{array}$ & $\begin{array}{c}10.2 \pm 8.4 \\
(0.0-28.1,15.3)\end{array}$ & $<0.001$ \\
\hline $\begin{array}{l}\mathrm{IL}-10(\mathrm{pg} / \mathrm{ml}) \\
\text { mean, SD } \\
\text { (range, median) }\end{array}$ & $\begin{array}{c}8.2 \pm 2.8 \\
(0.0-12.2,5.0)\end{array}$ & $\begin{array}{c}10.3 \pm 4.3 \\
(0.0-12.1,6.8)\end{array}$ & $<0.005$ \\
\hline $\begin{array}{l}\text { sICAM-1 (ng/ml) } \\
\text { mean, SD } \\
\text { (range, median) }\end{array}$ & $\begin{array}{c}363.2 \pm 53.4 \\
(130.2-428.3,130.0)\end{array}$ & $\begin{array}{c}205.0 \pm 44.3 \\
(0.0-301.0,84.5)\end{array}$ & $<0.001$ \\
\hline
\end{tabular}

CIMT - carotid intima-media thickness, IL-6-interleukin 6, TNF- $\alpha$ - tumour necrosis factor $\alpha, I L-10$ - interleukin 10, sICAM-1 - soluble intracellular adhesion molecule, * analysis of variance with one parameter, $p<0.05$
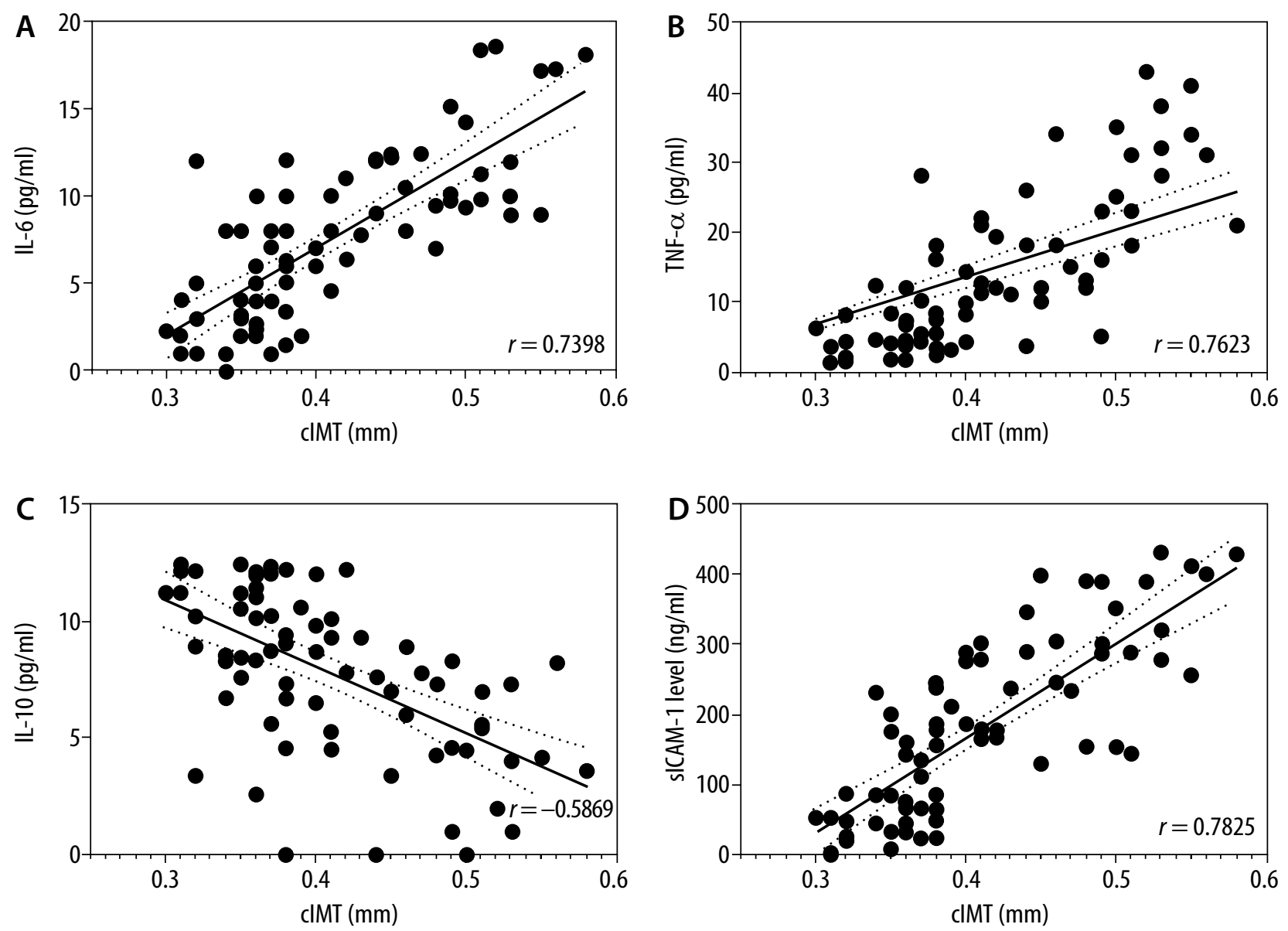

FIGURE 2. Correlation between mean carotid intima-media thickness (cIMT) and, respectively, IL-6 level (pg/ml), TNF- $\alpha$ level (pg/ml), IL-10 level (pg/ml), and sICAM-1 level ( $\mathrm{ng} / \mathrm{ml})$ in the whole group of patients

a higher prevalence of TTH in older teenagers described in our study is consistent with the observations of various authors [2,3].

The cIMT measurements of common carotid arteries have found a well-established place in estimating the risk of premature atherosclerosis in both adults and chil- dren $[11,16,17]$. These values increase with the patient's age (approximately 0.01-0.02 $\mathrm{mm}$ /year) and are slightly higher in boys than in girls of the same age [18-20]. In our study, the mean cIMT value increased from $0.37 \mathrm{~mm}$ in 14-year-old to $0.43 \mathrm{~mm}$ in 17 -year-old patients with TTH. During the observation period the mean cIMT val- 
ue in boys increased by $0.09 \mathrm{~mm}$ (from 0.38 to $0.47 \mathrm{~mm}$ ) and in girls by $0.05 \mathrm{~mm}$ (from 0.36 to $0.41 \mathrm{~mm}$ ).

In a multicentre study of a healthy paediatric population, Doyon et al. confirmed the occurrence of a difference in cIMT values according to the sex of children aged 15-18 years. The cIMT values of the 50 th percentile in a six-year-old was $0.37 \mathrm{~mm}$, regardless of the child's sex, but increased to $0.39 \mathrm{~mm}$ for girls and $0.41 \mathrm{~mm}$ for boys aged 18 years [10]. In the current study, the mean cIMT value in all studied adolescents was higher in boys than in girls, and it rose by $0.44 \mathrm{~mm}$ and $0.39 \mathrm{~mm}$, respectively. The differences according to sex were statistically significant in 16- and 17-year-old patients in group 1 and in 16-year-old patients in group 2.

Statistically significantly higher amounts of IL-6, TNF- $\alpha$, and sICAM- 1 were observed in patients from group 1 compared to the control group, while the inverse relationship was obtained for IL-10. Levels of the concentration of the cytokines were correlated to cIMT values in the whole group of tested children. Moreover, a positive correlation between cIMT value and the levels of IL-6, TNF- $\alpha$, and sICAM- 1 and a negative correlation between cIMT and the levels of IL-10 were found. These results could indicate that in examined patients with TTH the reason for the higher cIMT value was the inflammatory process in the vascular wall, which showed that proinflammatory cytokines such as IL-6, TNF- $\alpha$, and sICAM-1 were involved.

Besir et al., in a study of young adult migraine patients, showed similar results: a relationship between atherosclerosis and inflammation. In their study the patients had higher cIMT values and sICAM-1 levels than the healthy controls [21]. Some authors present endothelial dysfunction as the reason for higher values of cIMT, migraine headache, and syncope in children and young adults $[22,23]$.

\section{CONCLUSIONS}

TTH in adolescents is present in both sexes, with a slightly higher prevalence in girls. The cIMT was higher in boys than in girls. Moreover, the presented results indicate that the inflammatory process in the vascular wall could lead to the higher cIMT values and/or to TTH in adolescents.

\section{DISCLOSURE}

The authors declare no conflict of interest.

\section{REFERENCES}

1. Özge A, Bugdayci R, Sasmaz T, et al. The sensitivity and specificity of the case definition criteria in the diagnosis of a headache: a school-based epidemiological study of 5562 children in Mersin. Cephalalgia 2002; 22: 791-798.
2. Sillanpaa M, Piekkala P. Prevalence of migraine and other headaches in early puberty. Scand J Prim Health Care 1984; 2: 27-32.

3. Guidetti V, Lucchese F, Bellini B. Is the migraines female brain different? Some new evidence. Brain 2012; 135: 2311-2313.

4. Anttila P, Metsähonkala L, Aromaa M, et al. Determinants of a tension-type headache in children. Cephalalgia 2002; 22: 401-408.

5. Dyb G, Stensland S, Zwart JA. Psychiatric comorbidity in a childhood and adolescent headache. Curr Pain Headache Rep 2015; 19: 5.

6. Bellini B, Arruda M, Cescut A, et al. Headache and comorbidity in children and adolescents. J Headache Pain 2013, 14: 79.

7. Olson M, Chambers M, Shaibi G. Pediatric Markers of Adult Cardiovascular Disease. Curr Pediatr Rev 2017; 13: 255-259.

8. Tedgui A, Mallat Z. Cytokines in atherosclerosis: pathogenic and regulatory pathways. Physiol Rev 2006; 86: 515-581.

9. Touboul PJ, Hennerici MG, Meairs S, et al. Mannheim carotid intima-media thickness and plaque consensus (2004-2006-2011). An update on behalf of the advisory board of the 3rd, 4th and 5th watching the risk symposia, at the 13th, 15th and 20th European Stroke Conferences, Mannheim, Germany, 2004, Brussels, Belgium, 2006, and Hamburg, Germany, 2011. Cerebrovasc Dis 2012; 34: 290-296.

10. Doyon A, Kracht D, Bayazit AK, et al. Carotid Artery Intima-Media Thickness and Distensibility in Children and Adolescents. Hypertension 2013; 62: 550-556

11. Engelen L, Ferreira I, Stehouwer CD, et al. Collaboration RV for AM. Reference intervals for common carotid intima-media thickness measured with echo-tracking: relation with risk factors. Eur Heart J 2012; 34: 2368-2380.

12. Den Ruijter HM, Peters SA, Anderson TJ, et al. Common carotid intima-media thickness measurements in cardiovascular risk prediction: a meta-analysis. JAMA 2012; 308: 796-803.

13. Spence JD. Carotid ultrasound phenotypes are biologically distinct. Arterioscler Thromb Vasc Biol 2015; 35: 1910-1913.

14. Pollex RL, Spence JD, House AA, et al. A comparison of ultrasound measurements to assess carotid atherosclerosis development in subjects with and without type 2 diabetes. Cardiovasc Ultrasound 2005; 3: 15.

15. Pollex RL, Hegele R. Genetic determinations of carotid ultrasound traits. Curr Atheroscler Rep 2006; 8: 2006-2015.

16. Tołwińska J, Głowińska B, Urban M, Pieciukiewicz B. Ultrasonographic evaluation of atherosclerotic changes in carotid and brachial arteries in obese and hypertensive children. Przegl Lek 2005; 62: 1346-1351.

17. Beauloye V, Zech F, Tran HTM, et al. Determinants of early atherosclerosis in obese children and adolescents. J Clin Endocrinol Metab 2007; 92: 3025-3032.

18. Jourdan C, Wühl E, Litwin M, et al. Normative values for intimamedia thickness and distensibility of large arteries in healthy adolescents. J Hypertens 2005; 23: 1707-1715.

19. Jones DL, Rodriguez VJ, Alcaide ML, et al. Subclinical Atherosclerosis Among Young and Middle-Aged Adults Using Carotid Intima-Media Thickness Measurements. South Med J 2017; 110: 733-737.

20. Bohm B, Hartmann K, Buck M, Oberhoffer R. Sex differences of carotid intima-media thickness in healthy children and adolescents. Atherosclerosis 2009; 206: 458-463.

21. Basir FH, Kocer A, Dikici S, et al. The evaluation of atherosclerosis in migraine patients. Pain Pract 2013; 13: 41-45.

22. Avci AY, Akkucuk MH, Torun E, et al. Migraine and subclinical atherosclerosis: endothelial dysfunction biomarkers and carotid intima-media thickness: a case-control study. Neurol Sci 2019; 40: 703-711.

23. Sabri MR, Dehghan B, Yaghini O, et al. Endothelial dysfunction state in migraine headache and neutrally mediated syncope in chldren and young adults. J Res Mes Sci 2015; 20: 771-776. 